\title{
Principles of evaluation of effectiveness of information technology support
}

\section{Yurchik Peter Franzevich}

Russian Federation, Doctor of Technical Sciences, Professor, Department of «Automated Control Systems».

Moscow Automobile \& Road construction State Technical University, 125319, Russian Federation, Moscow, Leningradsky prospekt, 64. Tel.: +7 (499) 151-64-12. http://www.madi.ru

upf.madi@mail.ru

\section{Moe Ko Ko}

Republic of the Union of Myanmar, Postgraduate Student, Department of «Automated Control Systems».

Moscow Automobile \& Road construction State Technical University, 125319, Russian Federation, Moscow, Leningradsky prospekt, 64. Tel.: +7 (499) 151-64-12. http://www.madi.ru

\section{moekoko88@gmail.com}

\begin{abstract}
The article considers the use of PDM system and the methodology of evaluation of efficiency of introduction of PDM - technologies, account of the productive resources of the enterprise, product quality, competitiveness, the total capitalization of the enterprise; applied the ROI methodology for assessment of investment return.
\end{abstract}

Keywords: PDM-technology, Return On Investment (ROI), Net Present Value (NPV), the effectiveness of information support. 
ISSN 2306-1561

Автоматизация и управление в технических системах (АУТС) 2014. - №1.1(8). - C. 91-97.

DOI: $10.12731 / 2306-1561-2014-1-10$

\section{УДК 004.9:681.3}

\section{Принципы оценки эффективности применения технологий информационной поддержки}

\section{Юрчик Петр Францевич}

Российская Федерация, доктор технических наук, профессор кафедры «Автоматизированные системы управления».

ФГБОУ ВПО «Московский автомобильно-дорожный государственный технический университет (МАДИ)», 125319, Российская Федерация, г. Москва, Ленинградский проспект, д.64, Тел.: +7 (499) 151-64-12, http://www.madi.ru

upf.madi@mail.ru

\section{Моe Ко Ко}

Республика Союза Мьянма, аспирант кафедры «Автоматизированные системы управления».

ФГБОУ ВПО «Московский автомобильно-дорожный государственный технический университет (МАДИ)», 125319, Российская Федерация, г. Москва, Ленинградский проспект, д.64, Тел.: +7 (499) 151-64-12, http://www.madi.ru

\section{moekoko88@gmail.com}

Аннотация. В статье рассматриваются применение PDM-системы и методика оценки эффективности внедрения PDM- технологий, имеющая комплексный характер; учтены производственные ресурсы предприятия, качество продукции, конкурентоспособность, общая капитализация предприятия; применена методика ROI для оценки возврата инвестиций.

Ключевые слова: PDM-технология, показатель возврата инвестиций (ROI), чистая приведенная стоимость (NVP), эффективность информационной поддержки.

\section{1. Введение}

Чтобы сохранять и увеличивать конкурентоспособность предприятия, требуется серьезная автоматизация планирования и управления, а также модернизация проектноконструкторских и технологических бизнес-процессов на базе технологий информационной поддержки и, в частности, PDM-системы.

Одна из главных проблем при принятии решения о внедрении PDM-системы заключается в том, что ее внедрение требует значительных материальных затрат, а 
положительный эффект от ее применения не всегда очевиден. В связи с этим немаловажным является не только оценка результатов применения PDM-технологии, но и прогнозирование этих результатов для конкретного предприятия с учетом его специфики.

По мнению некоторых специалистов, применение PDM-систем приводит к существенной экономии и получению дополнительной прибыли, достигаемых за счет сокращения:

- сроков вывода новой продукции на рынок (до $75 \%$ );

- затрат на проектирование сложной продукции (до 30 \%);

- объема конструктивных изменений (до 70 \%);

- расходов на подготовку эксплуатационной и технической документации (до $30-40 \%)[2]$.

Существуют три основных уровня реализации системы информационной поддержки жизненного цикла изделия (ЖЦИ) на предприятиях:

- электронный архив технической документации предприятия;

- система электронного технического документооборота предприятия;

- система информационной поддержки ЖЦИ.

\section{2. Методика оценки эффективности от внедрения PDM- технологий}

Методика оценки эффективности внедрения PDM-технологий должна иметь комплексный характер: помимо экономии традиционно выделяемых производственных ресурсов предприятия (например, сырье, энергия, труд и др.) необходимо оценивать влияние новой организации работы на такие показатели предприятия, как качество продукции, новые методы обслуживания клиентов, и, в конечном счете, конкурентоспособность и общая капитализация предприятия[1].

Следовательно, комплексный характер методики должен показываться и при выборе показателей для оценки изменений. Поэтому предлагается комбинированное использование качественных и количественных показателей, что, рассчитывая эффект от внедрения PDM-системы, определяет эффективность внедрения не только самой системы PDM, но и новых принципов работы предприятия. Первое предполагает автоматизацию, что приводит к экономии ресурсов, и второе - организационную инновацию.

Для оценки экономической эффективности инвестиций в работы по реализации ЖЦИ, используются следующие группы методов.

1. Затратные методы:

- оценка единовременных затрат на внедрение и закупку программноаппаратных комплексов;

- оценка совокупной стоимости владения информационными системами (Total Cost of Ownership, TCO).

2. Стандартные экономические методы оценки эффекта: 
- оценка возврата инвестиций (Return on Investment, ROI);

- чистая приведенная стоимость проекта (NPV);

- отдача активов;

- цена акционера [3].

Оценка единовременных затрат на внедрение и закупку программно-аппаратных комплексов. Этот метод может использоваться для минимизации затрат при заранее ожидаемых результатах. Несмотря на все усилия аналитиков, консультантов и специализированных изданий, большинство предпринимателей и управленцев в России до сих пор интересуется только этими затратами. Видимые расходы включают в себя следующие группы затрат:

- капитальные затраты (на аппаратное и программное обеспечение);

- расходы на управление ИПИ-технологиями;

- расходы на техническую поддержку аппаратного и программного обеспечения (ПО);

- расходы на разработку прикладного ПО внутренними силами;

- командировочные расходы;

- расходы на услуги связи;

- другие группы расходов [3].

Показатель совокупной стоимости владения PDM-системой рассчитывается по формуле (1).

$$
T C O=\Pi p+K p_{1}+K p_{2},
$$

где

Пр - прямые расходы;

$K p_{1}$ - косвенные расходы первой группы;

$K p_{2}$ - косвенные расходы второй группы.

\section{3. Применение методика ROI}

Методика ROI рассчитывает коэффициент возврата инвестиций в инфраструктуру предприятия по формуле (2).

$$
R O I=\frac{\ni \Phi}{И}=\sum_{i=1}^{3} \frac{\ni \phi_{i}}{\mathrm{TCO}}
$$

где

$T C O$ - показатель совокупной стоимости владения PDM-системой;

Эф - суммарный эффект от внедрения ИТ;

$И$ - инвестиции в ИТ.

Для определения показателя NPV необходимо спрогнозировать величину финансовых потоков за каждый год проекта, а затем привести их к общему знаменателю для возможности сравнения во времени по формуле (3). 


$$
N P V=\sum_{i=1}^{n} \frac{C F_{i}}{1+r_{i}}-I_{0}
$$

где

$I_{0}$ - первоначальные инвестиции;

$C F_{i}$ - чистый поток средств в год $\mathrm{i}$;

$i$ - годовая ставка дисконта в год $\mathrm{i}$;

$N$ - период прогнозирования.

Отдача активов. Информационная система рассматривается как активы предприятия, которые должны приносить определенную отдачу. Эффективность использования капитала оценивается исходя из ставки альтернативной доходности (например, информационная система дает большую отдачу, чем вложения в высокодоходные акции).

$$
K=\frac{C_{\text {Д }}^{\text {ИT }}}{C_{\text {Д }}^{\text {АЛЬ }}},
$$

где

$K$ - коэффициент превышения ставки доходности PDM-системы над ставкой альтернативной доходности;

$C^{И T}$ д - ставка доходности PDM-системы;

$C^{A Л ь T}$ д - ставка альтернативной доходности.

Цена акционера. Данный метод является перспективным для применения в промышленности. В недалеком будущем стоимость акций компаний и привлечение новых акционеров будут определяться квалифицированностью компании в вопросах электронного бизнеса и широкого использования всех И Т, предлагаемых рынком. Собственники компании будут оценивать инвестиции в ИПИ-технологии как вложения в повышение капитализации своих компаний.

$$
Э \phi_{\text {аки }}=Э \phi /\left(Q_{\text {lаки }}-Q_{\text {окии }}\right)
$$

где

Э $\phi_{a \kappa и}$ - эффективность инвестиций в РDM-системы на привлечение одного акционера;

Эф - эффект от внедрения PDM-системы;

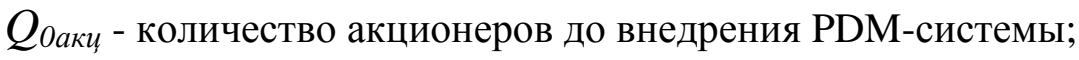

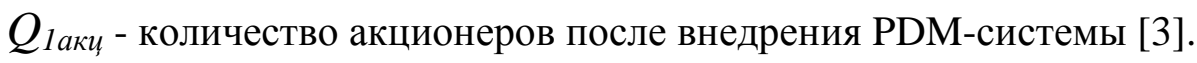

Основной методологический подход к оценке эффективности внедрения ИПИтехнологий заключается в статистической оценке результатов выполнения однородных процессов до и после внедрения системы или ее соответствующего этапа. При этом большое значение имеет выделение рассматриваемого процесса, учет его влияния на общие результаты предприятия, формирование однородной выборки исходных данных. Для каждого этапа ЖЦИ требуется определять свои показатели эффективности [1]. 
В качестве основных факторов эффективности автоматизации производственного процесса можно использовать:

- длительность разработки и согласования (проектирования) ТП;

- затраты на разработку и согласование (проектирование) технологических процессов;

- повышение качества изделия [3].

\section{4. Заключение}

В результате инвестиций в работы по реализации ЖЦИ, как правило, получают ускорение введения изменений в конструкторскую и технологическую документацию и уменьшение количества ошибок при автоматизации операций преобразования структуры информации. Но оценить количественно такое качественное улучшение в зависимости от характеристик операций информационной интеграции не представляется возможным. Поэтому при исследовании влияния каких-либо характеристик на эффективность производственного процесса учитывают в основном их влияние на трудоемкость и длительность процесса, предполагая, что их дополнительное положительное влияние на качество продукции только увеличит эффект от внедрения этих ИТ и позволит получить большую эффективность автоматизации [2].

\section{Список информационных источников}

[1] Абрамова И.Г. Эффективность внедрения РDM-систем на машиностроительных предприятиях / И.Г. Абрамова, Д.А. Абрамов, Р.М. Богомолов // Вестник Самарского государственного аэрокосмического университета. 2009. - №3. - С. 19.

[2] Авсянников Н.М. Инновационный менеджмент / Н.М. Авсянников. - М.: РУДН, 2002. - $523 \mathrm{c}$.

[3] Вертакова Ю.В. Управление инновациями: теория и практика / Ю.В. Вертакова, Е.С. Симоненко. М.: Эксмо-Пресс. 2008. - 432 с.

[4] Голубкова В.Б., Юрчик П.Ф., Гусеница Д.О. Применение интегрированных систем поддержки принятия решений для предотвращения сбоёв в работе прикладных информационных систем // Автоматизация и управление в технических системах. - 2013. - № 3(5). - C. 48-52. URL: auts.esrae.ru/5-98 (дата обращения: 27.01.2014).

[5] Гусеница Д.О., Юрчик П.Ф., Голубкова В.Б. Увеличение эффективности работы систем поддержки принятия решений с помощью интеграции прикладных информационных систем // Автоматизация и управление в технических системах. - 2013. - № 4.1. - С. 62-67. DOI: 10.12731/2306-1561-2013-4-11.

[6] Дмитров В.И. Опыт внедрения CALS за рубежом. // Автоматизация проектирования. - 1997. - № 1. - С. 2.

[7] Жарков Н.Н. Методы построения корпоративной информационной системы управления ресурсами строительного предприятия / Н.Н. Жарков, Т.В. Дорохина А.В. Остроух, Н.Е. Суркова // Вестник Российского нового университета. Серия естествознание, математика, информатика. - М.: РосНОУ, 2004. - Вып. 4. - С. 110113. 
[8] Ковшов А.Н. Информационная поддержка жизненного цикла изделий машиностроения: принципы, системы и технологии CALS-ИПИ/ Ковшов A.H.М.: Издательский центр «Академия», 2007.

[9] Колчин А.Ф., Овсянников М.В., Стрекалов А.Ф., Сумароков С.В. Управление жизненным циклом продукции. - М.: Анахарсис, 2002. - 304 с.

[10] Николаев А.Б. Информационные технологии в менеджменте и транспортной логистике: учебное пособие / А.Б. Николаев, А.В. Остроух. - Saint-Louis, MO, USA: Publishing House Science and Innovation Center, 2013. - 254 c. - ISBN 978-0615-67110-9.

[11] Остроух A.B. Проблемы и перспективы внедрения компонентов CALSтехнологии на промышленных предприятиях / А.В. Остроух, Д.И. Попов, Д.А. Буров // Научный вестник МГТУ ГА. Серия «Аэромеханика и прочность, поддержание летной годности ВС». - 2008. - №130. - С. 138-147.

[12] Остроух А.В. Основы построения систем искусственного интеллекта для промышленных и строительных предприятий: монография / А.В. Остроух. - М.: OОО «Техполиграфцентр», 2008. - 280 с. - ISBN 978-5-94385-033-2.

[13] Остроух А.В. Информационные технологии в научной и производственной деятельности / [ред. А.В. Остроух] - М: ООО "Техполиграфцентр", 2011. - 240 с. ISBN 978-5-94385-056-1.

[14] Остроух А.В. Системы искусственного интеллекта в промышленности, робототехнике и транспортном комплексе: монография / A.В. Остроух Красноярск: Научно-инновационный центр, 2013. - 326 с. - ISBN 978-5-90631410-9.

[15] Суркова Н.Е. Методы проектирования информационных систем / А.В. Остроух, Н.Е. Суркова. - М.: РосНОУ, 2004. - 144 с. - ISBN 5-89789-021-8.

[16] Юрчик П.Ф. Формализация задач принятия решений при управлении проектами обеспечения жизненного цикла автодорожных объектов / И.Н. Акиньшина, А.В. Остроух, А.Г. Соленов, П.Ф. Юрчик // Приборы и системы. Управление, контроль, диагностика. - М.: «Научтехлитиздат», 2007. - №3. - С. 13-18.

[17] Юрчик П.Ф. Выбор проектов обеспечения жизненного цикла автодорожных объектов / А.В. Остроух, П.Ф. Юрчик // Автомобильные дороги. - М.: ЗАО «Издательство дороги», 2011. - №2. - С. 30-31. 